\title{
In vitro production of bovine blastocyst with oocyte collected from abattoir ovary
}

\author{
GK Deb*, SR Dey, TN Nahar, MYA Khan, MM Rahman
}

Bangladesh Livestock Research Institute, Savar, Dhaka, Bangladesh

\begin{abstract}
This study was designed to adopt in vitro embryo production (IVP) protocol using abattoir ovary. Ovaries were collected from local abattoir; cumulus-oocyte-complexes (COCs) were aspirated from 3 to $8 \mathrm{~mm}$ diameter follicles using a $10 \mathrm{ml}$ disposable syringe attached with a $21 \mathrm{G}$ needle. The COCs were selected based on morphological characteristics and selected COCs were transferred into in vitro maturation (IVM) medium for 22 to 24 hrs. The matured COC were fertilized in vitro (IVF) using fresh semen capacitated through incubation with heparin sodium salt $(20 \mu \mathrm{g} / \mathrm{ml})$. After IVF, the presumed denuded zygotes were cultured in in vitro culture medium-I (IVC-I) for 3 days. After 3 days, the $\geq 8$ cell embryos were transferred into IVC-II medium until day 8 of embryonic development (day 0: day of IVF). Cleavage and blastocyst development rates were evaluated at day 3 and day 7. The maturation rates of COC were examined through detection of first polar body and cumulus cell expansion. Results showed that $74.16 \pm 5.49 \%$ of the total immature COCs were matured as detected by the presence of first polar body. The diameter of matured COC was 2.21 times higher than that of the immature COC. Moreover, about $64.30 \pm 6.71 \%$ COC showed full expansion of their cumulus cell. The cleavage rate of presumed zygotes was $62.05 \pm 7.07 \%$. Among the cleaved embryos, $26.67 \pm 11.78 \%, 10.84 \pm 6.13 \%$, $22.51 \pm 9.57 \%$ and $39.98 \pm 5.25 \%$ embryos were at 2-, 4-, 8- and 16 to 32-cell embryonic stages, respectively at day 3 . Blastocyst development rates were $14.95 \pm 4.39 \%$. This study inferred that the BLRI adopted culture system supports development of bovine embryo in vitro.
\end{abstract}

Key words: Bovine, in vitro maturation, cumulus cell expansion, cleavage, blastocyst

Bangladesh Animal Husbandry Association. All rights reserved. Bang. J. Anim. Sci. 2016. 45 (1): 31-35

\section{Introduction}

Cattle of Bangladesh are mostly indigenous type and about $35 \%$ of indigenous cattle were crossed with exotic high yielding dairy and beef breeds (DLS, 2013). Production performances of the cattle population are generally low though they possess higher genetic biodiversity and popularly known for their higher reproductive efficiency. However, a very small number of cows are yielding 2 to 3 times higher milk than their population average (Deb et al., 2012). In recent years, farmers are interested to raise high yielding cows rather than rearing number of low yielding cows. Therefore, rapid multiplication and distribution of existing available high yielding cows can increase milk production of the country within shortly. In vitro embryo production (IVP) and embryo transfer techniques are using in many developed and developing countries for rapid multiplication of high yielding cows.
The IVP technique accelerate genetic gain through increasing selection intensity and reducing generation interval (Camargo et al., 2005; Marquez and Garrick, 2007; Manjunatha et al., 2008). BLRI has undertaken research program to adopt IVP technology for multiplication of high yielding cows of Bangladesh since 2011. A consistent embryo culture, storage and transfer system to recipient cows is the prerequisite for application of IVP technology with the traditional cattle breeding program. The ovary of slaughtered female cattle is a cheap source of oocyte for research purposes and is commonly used for standardization of in vitro embryo production, embryo cryopreservation and embryo transfer to recipient heifer/cows protocols (Deb et al., 2011; Dey et al., 2011; Ha et al., 2013a and 2013b). Considering these facts, this study was designed to establish in vitro embryo production system using oocyte from abattoir cow ovaries. 
Deb et al., (2016) Bang. J. Anim. Sci. 45(1): 31-35

\section{Materials and methods}

\section{In vitro maturation}

Ovaries of slaughtered cows were collected from abattoir located at Mohammodpur, Dhanmondi, Dhaka in physiological saline $(0.90 \%)$ sodium chloride supplemented with $100.00 \mathrm{IU} / \mathrm{ml}$ penicillin and $0.10 \mathrm{~g} / \mathrm{ml}$ streptomycin sulfate) at ambient temperature and transported to the laboratory within 4 to $5 \mathrm{hrs}$ of slaughter. In the laboratory, extraneous tissue was removed and ovaries were washed with phosphate buffer saline (PBS). The cumulus-oocyte-complexes (COC) were aspirated using a $10 \mathrm{ml}$ disposable syringe attached with a $21 \mathrm{G}$ needle. The aspirated material was poured onto a $100.00 \mathrm{~mm}$ Petridis containing TL-HEPES $(114.00 \mathrm{~mm}$ sodium chloride, $3.20 \mathrm{~mm}$ potassium chloride, $2.00 \mathrm{~mm}$ sodium bicarbonate, $0.34 \mathrm{~mm}$ sodium biphosphate, $10.00 \mathrm{~mm}$ sodium lactate, $0.50 \mathrm{~mm}$ magnesium chloride, $2.00 \mathrm{~mm}$ calcium chloride, $10.0 \mathrm{~mm}$ HEPES, $1.00 \mu \mathrm{l} / \mathrm{ml}$ phenol red, 100.00 $\mathrm{IU} / \mathrm{ml}$ penicillin, and $0.10 \mathrm{mg} / \mathrm{ml}$ streptomycin) solution and the cumulus-oocyte-complexes (COC) were searched under a microscope at low magnification $(4 \mathrm{x})$.

The COCs possessing an even cytoplasm and covered with minimum 3 layers of compact cumulus cells were selected for in vitro maturation (Stojkovic et al., 2001). The selected $\mathrm{COC}$ (50 to 70 per well) were washed 2-3 times in TL-HEPES and $2-3$ times in IVM medium (TCM199 + 10.00\% FBS, $1.00 \mu \mathrm{g} / \mathrm{ml} \beta$-estradiol, $10.00 \mu \mathrm{g} / \mathrm{ml} \mathrm{FSH}, 0.60 \mathrm{~mm}$ cystein, and $0.20 \mathrm{~mm}$ sodium pyruvate) before placing them into a well of 4-well dish containing 500.00 to $700.00 \mu$ IVM medium for 22 to $24 \mathrm{hrs}$.

\section{In vitro fertilization}

The matured COCs were fertilized in vitro by fresh semen collected from BLRI cattle Breed-1 (BCB-1) using artificial vagina method. Hundred micro litters $(8.00$ to $10.00 \mu \mathrm{l})$ semen were placed in a $15 \mathrm{ml}$ conical tube containing 10.00 $\mathrm{ml} \mathrm{D-PBS}$ and pelleted by centrifugation at $750 \times \mathrm{g}$ for $5 \mathrm{~min}$. The supernatant was removed carefully and $10.00 \mathrm{ml}$ D-PBS was added in the tube. The sperm was washed for 2 to 3 times accordingly. Then sperm were capacitated through incubation with $500.00 \mu \mathrm{l}$ IVF medium (Tyrode's lactate solution supplemented with $6.00 \mathrm{mg} / \mathrm{ml}$ BSA, $22.00 \mathrm{\mu g} / \mathrm{ml}$ sodium pyruvate, $100.00 \mathrm{IU} / \mathrm{ml}$ penicillin, and $0.10 \mathrm{mg} / \mathrm{ml}$ streptomycin) containing heparin sodium salt $(20.00 \mu \mathrm{g} / \mathrm{ml})$ for 15 min. After capacitation, spermatozoa were diluted at approximately $1 \times 10^{6}$ spermatozoa $/ \mathrm{ml}$ with IVF medium. The matured COC were cocultured with capacitated spermatozoa for 18 to $20 \mathrm{hrs}$ through placing them into a well of 4well dish $(500.00$ to $700.00 \mu \mathrm{l})$.

\section{In vitro culture}

After IVF, the cumulus cells were removed by gentle pipetting into TL-HEPES and the denuded presumed zygotes were placed in the well of a four-well dish containing 500.00-700.00 $\mu \mathrm{l} \mathrm{CR1-}$ aa medium (Rosenkrans et al., 1993) supplemented with $44.00 \mu \mathrm{g} / \mathrm{ml}$ Na-pyruvate, $14.60 \mu \mathrm{g} / \mathrm{ml} \quad$ glutamine, $10.00 \mu \mathrm{l} / \mathrm{ml}$ penicillin/streptomycin, $3.00 \mathrm{mg} / \mathrm{ml} \mathrm{BSA}$ and $310.00 \mu \mathrm{g} / \mathrm{ml}$ glutathione for 3 days (IVC-I). These were then cultured until day 8 of embryonic development in a medium of the same composition, except that the BSA was replaced with $10.00 \%(\mathrm{v} / \mathrm{v}$ ) FBS (IVC-II). The incubation conditions during IVM, IVF and IVC were $5 \% \mathrm{CO}_{2}$ in air at $38.5^{\circ} \mathrm{C}$ with maximum humidity. The media (IVM, IVF and IVC) were pre-incubated for minimum two hours under culture condition.

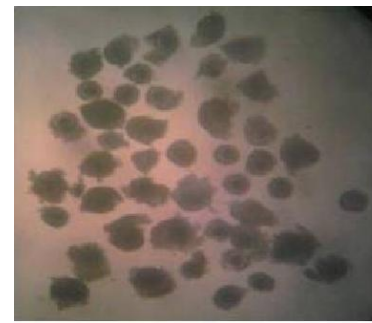

Immature COC tromsferred to [VM

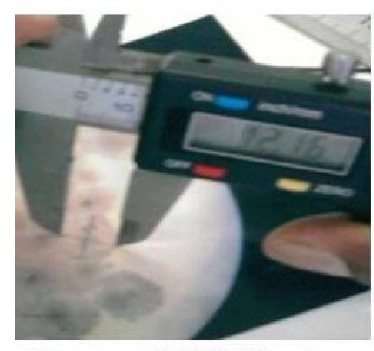

Measurement of COC danneter

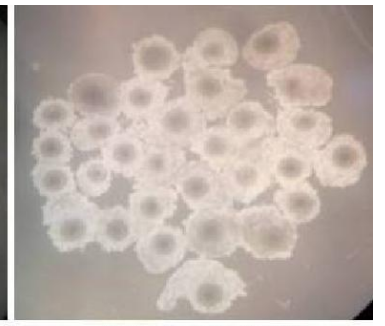

COC after 24h of IVM

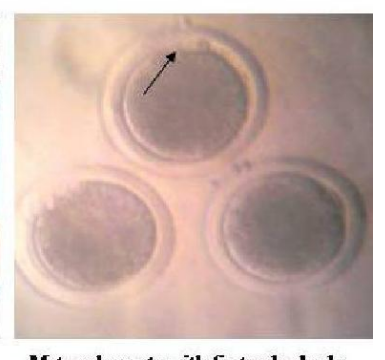

Figure 1. Detection of maturation rates after in vitro maturation of bovine cumulus-oocytecomplexes. Arrow head indicates presence of first polar body 


\section{In vitro production of bovine blastocyst}

\section{Efficiency of culture system}

The efficiency of the studied culture system was measured by evaluating i) maturation, ii) cleavage and iii) blastocyst development rates. The maturation rates of $\mathrm{COC}$ were examined through detection of first polar body under stereomicroscope (Dey et al., 2011) and cumulus cell expansion (Rahman et al., 2003). After maturation, the COCs were denuded and first polar body was checked under stereomicroscope. Measure on cumulus cell expansion was conducted according to Rahman et al. (2003). The COCs were graded into three groups according to cumulus cell expansion i.e. full (FE), medium (ME) and less (LE) expansions. Moreover, the diameters of $\mathrm{COC}$ at onset and after IVM were measured using slide calipers (Figure 1). The cleavage rate was calculated based on the number of presumed zygote transferred to IVC-I medium and number of the cleaved to at least 2cell embryonic stage. Similarly blastocyst development rates were calculated at day 8 on the basis of total blastocyst counted and presumed zygote transferred into the IVC-I medium. The data were represented in percentage.

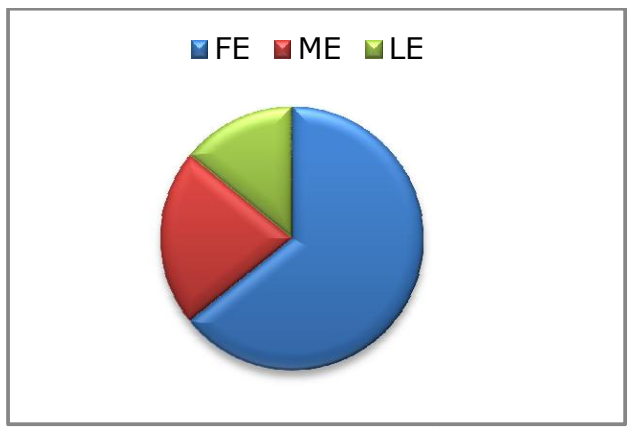

Figure 3. Cumulus cell expansion (\%) in bovine cumulus-oocyte-complexes matured in vitro. FE: full expansion, ME: Medium expansion and LE: least expansion

\section{Statistical analysis}

Eight replications for estimation of embryonic development rate (cleavage, 2-, 4-, 8- and $\geq 16$ cell embryonic stage) and that of three for blastocyst development rate were used. Mean and standard deviation was calculated using MS Excel.

\section{Results and Discussion}

The maturation rate following 22 to 24 hrs culture in IVM medium was $74.16 \pm 5.49 \%$ (142 out of 192) as detected by extrusion of first polar body (Figure 1). The diameter of immature and matured COCs was $6.19 \pm 0.91$ and $13.66 \pm 2.38$ $\mathrm{mm}$, respectively. The diameter of $\mathrm{COC}$ was increased 2.21 times following maturation in vitro. About $64.30 \pm 6.71 \%$ COCs showed full expansion of their cumulus cell during IVM (Figure 2). The cleavage rate was $62.05 \pm 7.07 \%$. Among the cleaved embryos, $26.67 \pm 11.78 \%$, $10.84 \pm 6.13 \%, 22.51 \pm 9.57 \%$ and $39.98 \pm$ $5.25 \%$ were at $2-, 4-, 8-$ and 16 to 32 -cell embryonic stages, respectively (Figure 3 and 4 ). Moreover, blastocysts development rate was $14.95 \pm 4.39 \%$ (Figure 4 ).

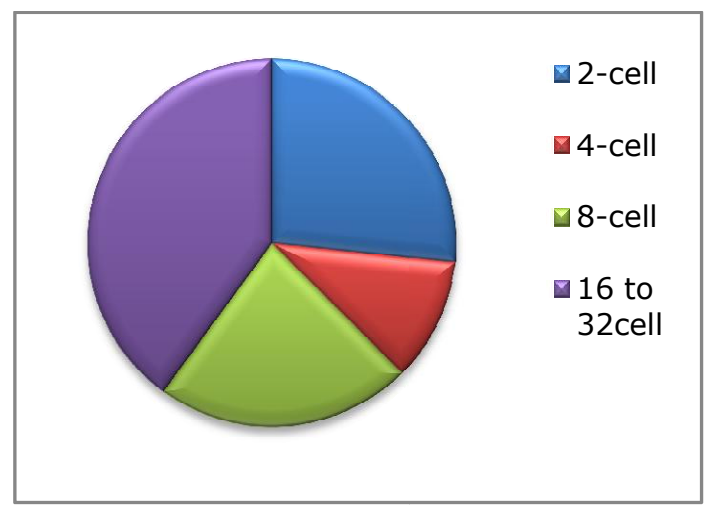

Figure 2. Development rates (\%) of bovine embryos at different embryonic stages observed at day 3 (day 0: day of in vitro fertilization)

Many developed and developing countries have been using IVP technique for increasing production performance of their cattle population since last couple of years. However, the IVP technology is still at research level in Bangladesh. BLRI has been conducting researches on IVP since 2011 to apply this technique with traditional cattle breeding system in Bangladesh. To our best knowledge, this is first time for Bangladeshi scientist to produce bovine blastocyst using COCs from slaughtered cows. The maturation, cleavage and blastocyst development rates of BLRI adopted IVP were $74.16 \pm 5.49 \%, 62.05 \pm$ $7.07 \%$ and $14.95 \pm 4.39 \%$, respectively. 
Deb et al., (2016) Bang. J. Anim. Sci. 45(1): 31-35

Maturation rates of COCs found in the current study are within the range of normal standard culture system. During IVM, 60.00 to $85.00 \%$ of the immature oocyte normally develops to metaphase II stage (Dey et al., 2011). Nuclear maturation of in vitro matured bovine oocyte is commonly evaluated through detection of first polar body in the perivaiteline region of the oocyte (Dey et al., 2011). Immature oocytes are generally arrested at deplotene stage and resume their meiosis during maturation period. Resumption of meiosis is essential for preparation of the oocyte for fertilization. The fist polar body is extruded during meiosis process and it indicates completion of the first meiotic division in oocytes. Diameter and cumulus cell expansion of $\mathrm{COC}$, associated with maturation of oocytes were also evaluated for monitoring maturation rates of COC. As maturation progress, the diameter of COC is increased. Degree of cumulus cell expansion is associated with in vitro oocyte maturation rate (Rahman et al., 2003; Jahan et al., 2012). This study also revealed that cumulus cell expansion is also associated with maturation status of oocyte. Collectively, these results showed that the BLRI adopted IVP is enable to support normal maturation of bovine COC in vitro.

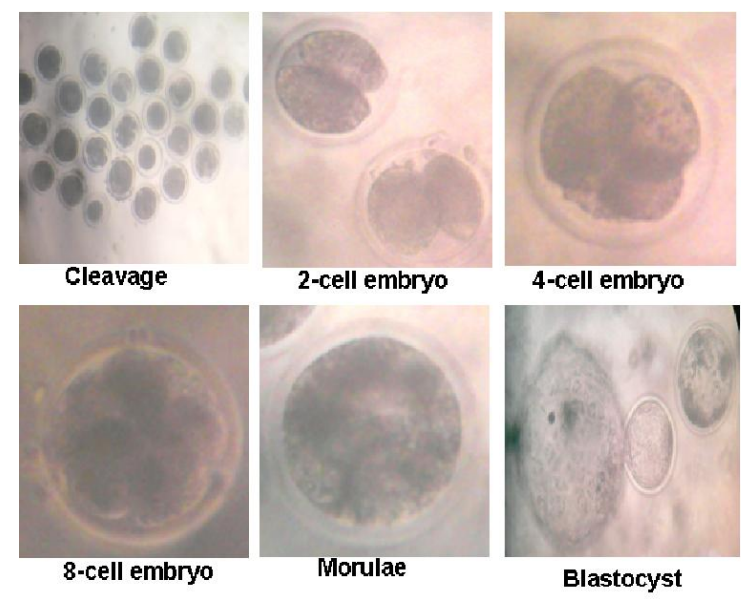

Figure 4. Bovine in vitro produced embryos at different developmental stages

Development rates to cleavage and blastocyst was lower in the current study than standard culture system (Dey et al., 2011). However, some reports showed similar and/or lower cleavage rates compared to present study (Livingston et al., 2014). Among the cleaved embryos, $26.67 \pm 11.78 \%, \quad 10.84 \pm 6.13 \%$, $22.51 \pm 9.57 \%$ and $39.98 \pm 5.25 \%$ were at $2-$, 4-, 8- and 16 to 32- cell embryonic stages, respectively. The efficiency of in vitro embryo development depends on oocyte donor, semen quality, and culture media and culture conditions employed during each phase of IVP (Brum et al., 2005). Beside these factors, the IVP efficiency is also affected by osmolality of media (Gordon, 1994), water quality used in different steps of IVP (Fukuda et al., 1987) and gasing level of incubator (Wang, 1991) among others. In this study, osmolality of different media was not checked due to lack of equipment facility. The $\mathrm{CO}_{2}$ level was recorded through monitoring display system of the incubator. The actual internal $\mathrm{CO}_{2}$ level of incubator was not confirmed through using externally measurable devices. In some cases, the display system of incubator may not show actual internal condition. Therefore, the low embryonic development of this study might be associated with incubation condition $\left(\mathrm{CO}_{2}\right.$ level and temperature), media osmolality and other uncontrolled factors.

\section{Conclusion}

The present culture system supports normal in vitro maturation of immature oocytes and subsequent embryonic development to blastocyst stage. Therefore, this culture system may be used with traditional cattle genetic improvement programme of the country.

\section{References}

Brum DS., Leivas FG., Silva CAM., Rubin MIB., Rauber LP., Fialho SS. (2005). The effects of number of oocytes and the volume of maturation medium in bovine in vitro embryo production. Animal Reproduction. 2: 70-73.

Camargo LS., Viana JH., Sa WF., Ferreira AM., Vale Filho VR. (2005). Developmental competence of oocytes from prepubertal Bos Indicus crossbred cattle. Animal Reproduction Science, 85: 53-59.

Deb GK., Dey SR., Alam MK., Sarker NR., Khondoker MAMY., Rahman MM. (2012). Establishment of in vitro embryo production system with slaughterhouse 


\section{In vitro production of bovine blastocyst}

ovaries. Proceedings of the Annual Research Review Workshop held in Bangladesh Livestock Research Institute, Savar, Dhaka during 22-23 June 2012.

Deb GK., Dey SR., Bang JI., Cho SJ., Park HC., Lee JG., Kong IK. (2011). 9-cis retinoic acid improves developmental competence and embryo quality during in vitro maturation of bovine oocytes through the inhibition of oocyte tumor necrosis factor-alpha gene expression. Journal of Animal Science. 89:2759-67.

Dey SR., Deb GK., Ha AN., Lee JI., Bang JI., Lee KL., Kong IK. (2011). Coculturing denuded oocytes during the in vitro maturation of bovine cumulus oocyte complexes exerts a synergistic effect on embryo development. Theriogenology. 7:1064-77.

DLS (2013). Report on Achievements in Livestock Sector during 2012-2013, Department of Livestock Sector. http://old.dls.gov.bd/DLS\%20successpresentation.pdf.

Fukuda A., Noda Y., Tsukui S., Matsumoto H., Yano J., Mori T. (1987). Influence of water quality on in vitro fertilization and embryo development for the mouse. Journal of In Vitro Fertilization and Embryo Transfer. 4: 40-45.

Gordon I. (1994). Laboratory Production of Cattle Embryo. CAB International, Wallingford, Oxon OX 108 DE, UK.

Ha AN., Park HS., Jin JI., Lee SH., Ko DH., Lee DS., White KL., Kong IK. (2013a). Postthaw survival of in vitro-produced bovine blastocysts loaded onto the inner surface of a plastic vitrification straw. Theriogenology. 81:467-473.

Ha AN., Lee SR., Jeon JS., Park HS., Lee SH., Jin JI., Sessions BR., Wang Z., White KL., Kong IK. (2013b). Development of a modified straw method for vitrification of in vitro-produced bovine blastocysts and various genes expression in between the methods. Cryobiology. 68:57-64.

Jahan N., Ahmed S., Fruque MO., Khandoker MAMY. (2012). Collection, grading and evaluation of buffalo cumulus-oocytecomplexes for in vitro maturation. Bangladesh Journal of Livestock Research. 18: 1-6.

Livingston T., Eberhardt D., Edwards JL., Godkin J. (2004). Retinol improves bovine embryonic development in vitro. Reproductive Biology and Endocrinology, 2:83.

Manjunatha BM., Ravindra JP., Gupta PS., Devaraj M., Nandi S. (2008). Oocyte recovery by ovum pick up and embryo production in river buffaloes (Bubalus bubalis). Reproduction in Domestic Animal. 43: 477-480.

Marquez GC., Garrick DJ. (2007). Selection intensities, generation interval and population structure of Red Angus cattle. Proceedings Western Section, American Society of Animal Science. 58: 55-58.

Rahman MGM., Goswami PC., Khandoker KAMY., Tareq MA., Ali ZZ. (2003). Collection of cumulus-oocyte-complexes from slaughterhouse ovaries in Bangladesh. Pakistan Journal of Biological Sciences. 6: 2054-2057.

Rosenkrans CFJr., Zeng GQ., MCNamara GT., Schoff PK., First NL. (1993). Development of bovine embryos in vitro as affected by energy substrates. Biology of Reproduction. 49:459-462.

Stojkovic M., Machado SA., Stojkovic P., Zakhartchenko V., Hutzler P., Goncalves PB., Wolf E. (2001). Mitochondrial distribution and adenosine triphosphate content of bovine oocytes before and after in vitro maturation: correlation with morphological criteria and developmental capacity after in vitro fertilization and culture. Biology of Reproduction. 64: 904-909.

Wang S., Y. Liu, GR. Holyoak, TD. Bunch. (1997). The effect of bovine serum albumin and fetal bovine serum on the development of pre-and post cleavage-stage bovine embryos cultured in CR2 and M199 media. Animal Reproduction Science. 48: 37-45. 